Article

\title{
Plasma Treatment Reduced the Discoloration of an Acrylic Coating on Hot-Oil Modified Wood Exposed to Natural Weathering
}

\author{
Arash Jamali ${ }^{1,2}$ and Philip D. Evans ${ }^{1,3, *}$ \\ 1 Centre for Advanced Wood Processing, Faculty of Forestry, University of British Columbia, Vancouver, \\ BC V6T 1Z4, Canada; arash.jamali@u-picardie.fr \\ 2 Plateforme de Microscopie Electronique, Université de Picardie Jules Verne, 80039 Amiens, France \\ 3 Department of Applied Mathematics, Research School of Physics, The Australian National University, \\ Canberra, ACT 0200, Australia \\ * Correspondence: phil.evans@ubc.ca
}

Received: 28 January 2020; Accepted: 3 March 2020; Published: 8 March 2020

\begin{abstract}
We test the hypothesis that plasma-treatment will remove oil from the surface of hot-oil modified blue-stained pine wood, and improve the adhesion and outdoor performance of a white acrylic coating on the modified wood. Modified wood was treated with water-vapour plasma, and microstructural changes at wood surfaces were examined. Plasma treatment removed oil from the surface of modified wood and etched bordered pits. The contact angle of water droplets on modified wood was $91.8^{\circ}$, but plasma-treatment for only $33 \mathrm{~s}$ reduced contact angle to less than that of the unmodified control $\left(48.6^{\circ}\right)$. The adhesion of the acrylic paint to modified wood was unaffected by plasma-treatment, but the adhesion rating of coated samples tested wet was slightly lower (3.1) than that of the coating on samples tested dry (3.5). The lightness value (CIE-L) of the acrylic coating on hot-oil modified wood samples exposed outdoors for 18 months was significantly lower (darker, 65.5) than that of the coating on similarly modified and exposed samples pre-treated with plasma (75.8). We conclude that plasma-treatment shows promise as a way of removing oil from the surface of hot-oil modified wood and reducing the discolouration of an acrylic coating on modified wood exposed to natural weathering.
\end{abstract}

Keywords: wood; plasma; pine; thermal modification; oil; blue stain; weathering; discolouration; adhesion; bordered pits

\section{Introduction}

The performance of coatings on hydrophobic materials such as plastics can be improved by treating the surface of the material with plasma, a reactive mixture of charged particles [1,2]. For example, plasma treatments are widely used by industry as a pre-treatment to increase wettability and adhesion of coatings to plastic automotive components [2,3]. Plasma treatment of wood prior to coating is unnecessary because wood is not normally hydrophobic, but there are exceptions. Wood that has been heat-treated at temperatures of $180-220{ }^{\circ} \mathrm{C}$ to reduce its susceptibility to fungal decay and moisture-induced deformation is hydrophobic [4-6]. Accordingly, there has been interest in using plasma treatments to reverse the effects of heat treatment (thermal modification) on the surface hydrophobicity of wood [7-11]. Plasma treatment of thermally modified wood has positive effects on both wettability [7-11], and coating adhesion [11]. These findings were obtained using wood that was thermally modified in air/steam or nitrogen [7-11]. However, wood can also be thermally modified using oil as the heating medium [12]. To our knowledge, there have been no studies of the effects of plasma treatment on wood that has been thermally modified in hot-oil. A previous study used plasma 
to treat wood surfaces that had been brush-coated with paraffin oil, but the aim of this research was to cross-link the oil and create a hydrophobic barrier, rather than modify the wood surface [13].

Oil modification treatments involve heating wood in vegetable oil (linseed, soy, sunflower, etc.) at temperatures of $180-220^{\circ} \mathrm{C}$ for various periods of time [5]. The hygroscopic components of wood are degraded during this heating period, and the wood absorbs oil, resulting in a hydrophobic material, which, like wood that has been thermally modified in air or nitrogen, is less susceptible to moisture-induced deformation and fungal decay [12]. Oil at the surface of hot-oil modified wood can reduce its wettability [14], and also the adhesion of coatings to wood [15]. An additional concern is that oil could migrate through coatings and encourage mould growth. In accord with this suggestion, low molecular weight wood extractives are able to migrate through coatings [16]. Furthermore, hot-oil modified wood is susceptible to colonization by mould fungi [17]. Oils also encourage pickup and retention of dirt at the surface of materials [18]. However, oils can be removed from surfaces by plasma, and there are several papers that have successfully used plasma to remove oily lubricants from metals and polymers $[19,20]$. Plasma cleaning systems have replaced solvent cleaning systems in some applications (decontamination of oxidized metal surfaces, cleaning of coins and degreasing of oily metal sheets) because they do not generate waste that requires disposal [21]. Solvent wiping is used to remove oil from oily woods such as teak (Tectona grandis L.f.), and to improve the performance of coatings on teak wood [22]. The novelty of this work lies in its potential to assist with the development of a solvent-free method of improving the performance of coatings on oily wood substrates.

We hypothesize that plasma treatment will remove residual oil from the surface of hot-oil modified wood and this will have beneficial effects on the wettability, adhesion and performance of an acrylic coating on wood. We test this hypothesis here. We chose blue-stained, mountain pine beetle-affected lodgepole pine wood (Pinus contorta Douglas) as our substrate because large volumes of this wood are available in Canada due to the unprecedented climate-hastened infestation of boreal forests by mountain pine beetle (Dendroctonus ponderosae Hopkins), and the salvage-harvesting of diseased pine trees in affected forests [23]. Furthermore, there is significant industry interest in hot-oil treatments as a way of making blue-stained wood more suitable for outdoor applications including cladding, which requires coating [24].

\section{Materials and Methods}

\subsection{Experimental Design and Preparation of Wood Samples}

Two separate experiments were carried out that examined the effects of plasma treatments on: (1) wettability and adhesion of an acrylic primer to hot-oil modified blue-stained wood (Table 1);

(2) exterior performance of an acrylic coating system on hot-oil modified wood (Table 2).

Table 1. Treatments, sample sizes, and replication for an experiment that examined the effects of plasma treatment on the wettability and adhesion of a white acrylic primer to hot-oil modified blue stained lodgepole pine wood.

\begin{tabular}{|c|c|c|c|c|}
\hline \multirow{2}{*}{$\begin{array}{l}\text { Plasma Treatment } \\
\text { Time, Seconds }\end{array}$} & \multicolumn{2}{|c|}{ Wettability } & \multicolumn{2}{|c|}{ Dry and Wet Adhesion Tests } \\
\hline & Sample Size, $\mathrm{mm}^{3}$ & Replication & Sample Size, $\mathrm{mm}^{3}$ & Replication * \\
\hline 0 & $3 \times 15 \times 38$ & 5 & $3 \times 15 \times 19$ & $5+5$ \\
\hline 33 & $3 \times 15 \times 38$ & 5 & $3 \times 15 \times 19$ & $5+5$ \\
\hline 333 & $3 \times 15 \times 38$ & 5 & $3 \times 15 \times 19$ & $5+5$ \\
\hline 667 & $3 \times 15 \times 38$ & 5 & $3 \times 15 \times 19$ & $5+5$ \\
\hline 1333 & $3 \times 15 \times 38$ & 5 & $3 \times 15 \times 19$ & $5+5$ \\
\hline
\end{tabular}

${ }^{*}$ Equal numbers (5) of replicates were used for adhesion tests performed on dry and wet samples.

For the first experiment, five eight foot long $(2438 \mathrm{~mm}) 2^{\prime \prime} \times 4^{\prime \prime}$ blue-stained lodgepole pine studs were purchased from Home Depot in Richmond, British Columbia. These parent studs were each 
cross-cut to produce a board that was 38 (radial) $\times 89$ (tangential) $\times 240$ (longitudinal) $\mathrm{mm}^{3}$ in size, free of defects, and with growth rings oriented tangentially to its wide faces. These boards provided replication at the higher level. Boards were conditioned at $20 \pm 1{ }^{\circ} \mathrm{C}$ and $65 \pm 5 \%$ r.h. for one week and modified with hot-oil (see below). Modified boards were sawn to produce $3 \mathrm{~mm}$ thick veneer samples, which were allocated at random to the different plasma treatments (Table 1). The wettability of modified and plasma treated samples was measured (see below). Samples were brush-coated with a water-borne primer (CIL Dulux acrylic latex), sawn in half and allocated to either dry or wet adhesion tests. The resulting experimental design accounted for random variation between boards (blocks) and between and within samples.

For the second experiment, eight conditioned blue-stained lodgepole pine studs, as above (eight experimental blocks) were sawn into four defect-free samples measuring 38 (radial) $\times 89$ (tangential) $\times 55$ (longitudinal) $\mathrm{mm}^{3}$, and assigned to the different treatments (Table 2). Veneer samples, $3 \times 17$ $\times 55 \mathrm{~mm}^{3}$ in size were sawn from modified and/or plasma-treated samples and brush-coated with an acrylic latex finishing system (CIL Dulux acrylic latex primer and top coat, one coat each). The paint used as a top coat was 'mildew resistant' and contained a fungicide, but information on the type and quantity of fungicide in the paint is not known. We chose an acrylic paint system because it is representative of those commonly used on wood cladding (siding). Furthermore, previous research has shown that acrylic paint is susceptible to mould even when the formulation contains fungicide $[25,26]$. Samples were randomly assigned to "weathering" or the non-weathered controls. Separate wood samples were prepared for scanning electron microscopy and confocal profilometry (see below).

Table 2. Treatments, sample sizes and replication for an experiment that examined the effects of hot-oil modification and plasma treatment on the water absorption and colour (CIE L value) of blue-stained lodgepole pine samples coated with a white acrylic paint system and exposed to natural weathering for 18 months (unexposed samples acted as a control).

\begin{tabular}{cccc}
\hline \multirow{2}{*}{ Treatment } & Sample Size, $\mathbf{m m}^{\mathbf{3}}$ & \multicolumn{2}{c}{ Replication Unweathered and Weathered Samples * } \\
\cline { 2 - 4 } & & Water Absorption Test & Colour Test \\
\hline Untreated & $3 \times 17 \times 55$ & $8+8$ & $8+8$ \\
Hot oil & $3 \times 17 \times 55$ & $8+8$ & $8+8$ \\
Hot oil/plasma & $3 \times 17 \times 55$ & $8+8$ & $8+8$ \\
Plasma & $3 \times 17 \times 55$ & $8+8$ & $8+8$ \\
\hline
\end{tabular}

* Equal numbers (8) of replicates were used for tests performed on weathered and unweathered samples.

\subsection{Hot-Oil Modification and Plasma Treatment of Wood Samples}

Wood was thermally modified by placing pre-weighed and conditioned samples in a circulating oil-bath (Model HTB, Thermoline Scientific Equipment Pty Ltd., Wetherill Park, Sydney, Australia) containing soya-bean oil at $220^{\circ} \mathrm{C}$. Modified wood was removed from the oil bath after $2 \mathrm{~h}$ and blotted on paper towels to remove excess oil. Hot-oil modified blue-stained wood and unmodified wood samples (described above) were plasma-treated in a reactor designed to clean silicon wafers to produce high-energy surfaces $[27,28]$. One wood sample was placed in the chamber of the plasma reactor at a time, and a vacuum of $0.15 \pm 0.01$ Torr was drawn. A valve was opened to allow water vapour from a glass reservoir into the chamber and the vacuum was redrawn. Radio frequency energy at $125 \mathrm{kHz}$ was transmitted to the treatment chamber for different periods of time (33, 333, 667, and $1333 \mathrm{~s})$. Samples subjected to vacuum acted as a control. After treatment, the chamber was vented to atmosphere. Samples were removed from the chamber, taking care to avoid touching and contaminating their upper surfaces.

\subsection{Contact Angle and Adhesion Measurements}

The wettability of the hot-oil modified and plasma treated wood was assessed by measuring the contact angle of $5 \mu \mathrm{L}$ droplets of distilled water on three spots on wood surfaces. A $5 \mu \mathrm{L}$ droplet 
of distilled water was placed on the wood surface using a syringe, after adjusting the needle of the syringe so it produced a sessile drop [28]. The static contact angle of the droplet on the sample was measured using an optical tensiometer (KSV CAM 101, KSV Instruments Ltd., Helsinki, Finland). Images of the droplets captured after 160 milliseconds were used to calculate the contact angles that water droplets made with wood surfaces. Contact angles were calculated using instrument software by baseline adjustment and curve fitting of the captured drop profile to the theoretical shape predicted by the Young-Laplace equation (KSV Instruments Ltd., Helsinki, Finland). Left and right contact angles were averaged to obtain a mean contact angle for each measurement. The contact angle was measured on three different locations for each specimen. Droplets were wiped from the surface of samples, and samples were air dried for $30 \mathrm{~min}$. They were then brush-coated with one coat of an acrylic primer (CIL Dulux primer), in accord with manufacturer's instructions. The finished samples were sawn into two and kept in a conditioning room for one week. The samples used for the wet adhesion test were sealed on their uncoated faces and edges with two-part epoxy resin (G2, Industrial Formulators of Canada Ltd., Burnaby, BC, Canada) to reduce water uptake by uncoated areas. After curing for $48 \mathrm{~h}$, samples for wet adhesion tests were weighed, floated on water on the coated (painted) side for $72 \mathrm{~h}$, and reweighed. The dry and wet adhesion of the coatings on hot-oil modified and plasma treated wood and controls was assessed using a cross-hatch tape test [29]. Samples were held firmly in a jig and then six cross-cuts, $1 \mathrm{~mm}$ apart, were manually inscribed on coated surfaces using a scalpel, guided by a steel ruler. Detached flakes or ribbons of coating were removed from coated surfaces with a soft brush. A strip of pressure-sensitive tape (3M pressure-sensitive adhesive packaging tape, $3 \mathrm{M} \mathrm{Co.,} \mathrm{Maplewood,} \mathrm{MN,} \mathrm{USA)} \mathrm{was} \mathrm{placed} \mathrm{over} \mathrm{the} \mathrm{cross-hatched} \mathrm{area} \mathrm{and} \mathrm{then}$ pulled off as described in ASTM D 3359 [30]. The cross-hatched area was scanned using a desktop scanner (Microtek Scan Maker i800, Microtek International Inc., Hsinchu, Taiwan), and digital (TIFF) images were obtained. These images were used to assess the adhesion of coatings on each sample ranking them from 0 (no adhesion, $>65 \%$ of paint removed from cross-hatched area) to 5 (complete adhesion, $0 \%$ of paint removed from cross-hatched area) [30]. Analysis of variance was used to assess the effects of plasma treatment on contact angle, and treatment and testing condition (dry v. wet) on paint adhesion. Statistical computation was performed using Genstat (v. 20). Contact angle results are presented in a graph and error bars on the graph ( \pm standard error of difference) can be used to estimate whether differences between individual means are statistically significant at the $5 \%$ level $(p<0.05)[31]$.

\subsection{Scanning Electron Microscopy and Confocal Profilometry}

Scanning electron microscopy was used to examine the effects of oil modification and plasma treatment on the micro-structure of blue-stained lodgepole pine wood. Samples measuring $15 \times 15$ $\times 30 \mathrm{~mm}^{3}$ were cut from blue-stained lumber studs, as above. These small blocks were soaked in distilled water for three days and individual blocks were clamped in a small vice beneath the stage of a low power binocular microscope (Nikon 69480, Nikon Vision Co., Ltd., Shinagawa-ku, Tokyo, Japan) with their radial face uppermost. A sharp single-edged razor blade (Type S35, Feather Safety Razor Co., Osaka, Japan) was used to slice by hand, thin $(20-30 \mu \mathrm{m})$ sections from the radial longitudinal face of each specimen until a clean, undamaged, surface was obtained [32]. Samples were dried over silica gel at $20 \pm 1{ }^{\circ} \mathrm{C}$ for $24 \mathrm{~h}$. Three types of samples were prepared using procedures described above: (1). Unmodified blue-stained lodgepole pine wood; (2) Hot-oil modified blue-stained lodgepole pine wood; (3) Hot-oil modified blue-stained lodgepole pine wood treated with plasma for different times, varying from $333 \mathrm{~s}$ to $1333 \mathrm{~s}$ (described above). Samples were dried over silica gel at $20 \pm 1{ }^{\circ} \mathrm{C}$ for $24 \mathrm{~h}$ and reduced in size to $\sim 5 \times 5 \times 8 \mathrm{~mm}^{3}$ using single-edged razor blades (Gem surgical carbon steel blades, American Safety Razor Co. Verona, VA, USA). They were then glued to separate aluminium stubs using Nylon nail polish as an adhesive. The stubs were sputter coated with an $8 \mathrm{~nm}$ layer of gold and they were then examined using a Hitachi S-2600 variable pressure scanning electron microscope (Hitachi Ltd., Chiyoda, Tokyo, Japan) at accelerating voltages of 5-6 kV. Secondary electron images of 
samples were obtained and saved as TIFF files. Non-contact surface profilometry was used to probe the surface structure of hot-oil modified and plasma treated blue-stained lodgepole pine wood [27]. Samples measuring $3 \times 15 \times 30 \mathrm{~mm}^{3}$ were cut from the radial surfaces of hot-oil modified blue-stained lodgepole pine wood. An area measuring $1.5 \times 1.5 \mathrm{~mm}^{2}$ was marked on the radial surface of each sample, and an AltiSurf $500^{\circledR}$ profilometer (Altimet, 298 Allée du Larry, 74200, Marin, France) was used to image the wood in this area. These samples were then treated with plasma, as above, and the marked surfaces were re-imaged. The software Papermap was used to produce topographical images of oil-modified and plasma-treated wood surfaces.

\subsection{Exposure of Samples to Natural Weathering and Evaluation of Coating Performance}

The edges of coated samples were sealed using two-part epoxy resin (G2, Industrial Formulators of Canada Ltd., Burnaby, BC, Canada). The samples were then placed on glass backing plates $(750 \times 120 \mathrm{~mm})$ and secured against the glass plates by clamping the edges of the samples between two glass strips using alligator clips. Samples were exposed to the weather on a rack inclined at $45^{\circ}$ to the vertical and facing south in Vancouver, BC, Canada for a period of 18 months. A matching set of samples was kept in a conditioning room for the duration of the weathering trial. After the weathering trial, samples were removed from the weathering rack, and kept in a conditioning room for one week. The CIE L value (lightness on a scale of 100 (white) to 0 (black)) of the white acrylic paint was measured in the middle of each sample using a spectrophotometer (CM-2600d, Minolta Co. Ltd., Osaka, Japan) [33]. The water absorption of coated samples (weathered and controls) was measured as follows. Samples were weighed using an analytical balance (AAA 300L, B.C. Scale Co. Ltd., Vancouver, BC, Canada) and a $100 \mu \mathrm{L}$ droplet of distilled water was placed on each sample using a single-channel pipette. After $60 \mathrm{~s}$, the water droplet was wiped off the surface of the sample with soft paper tissue and the sample was re-weighed. The weight of water absorbed by the surface was calculated as described by Kiguchi and coworkers and expressed as the ratio of weight of water absorbed by weathered samples to that of unweathered controls [34]. Analysis of variance was used to assess the effects of hot-oil modification and/or plasma treatment and exposure to natural weathering on CIE L value and water absorption. Lightness results are presented in a graph and an error bar (Fisher's least significant difference, LSD) on the graph can be used to estimate whether differences between individual means are statistically significant at the 5\% level $(p<0.05)$ [31].

\section{Results}

\subsection{Contact Angle and Adhesion Measurements}

Hot-oil modified blue-stained lodgepole pine wood was hydrophobic as water droplets formed contact angles with modified wood surfaces that were greater than $90^{\circ}(0 \mathrm{~s}$ in Figure 1). Plasma treatment for only $33 \mathrm{~s}$ made the surface of hot-oil modified wood slightly more wettable than unmodified wood. Increasing the treatment time to $333 \mathrm{~s}$ further increased wettability, but thereafter there was no significant $(p>0.05)$ effect of treatment time on wettability (Figure 1$)$. We measured the adhesion of an acrylic primer to hot-oil modified and plasma treated samples using a cross-cut adhesion test. There was no significant $(p>0.05)$ effect of plasma treatment on adhesion, and no significant $(p>0.05)$ interaction of plasma treatment and testing condition (dry vs. wet) on adhesion. However, there was a small, but statistically significant $(p=0.026)$ effect, of testing condition on adhesion when results were averaged across different treatments. The average adhesion rating for samples in the dry condition was 3.5 (good to very good adhesion) versus 3.1 (good adhesion) for samples tested in the wet condition (least significant difference was 0.349). Photographs of a representative set of cross-hatched, adhesion-tested samples can be found in the Supplementary Materials associated with this paper (Figure S1). 


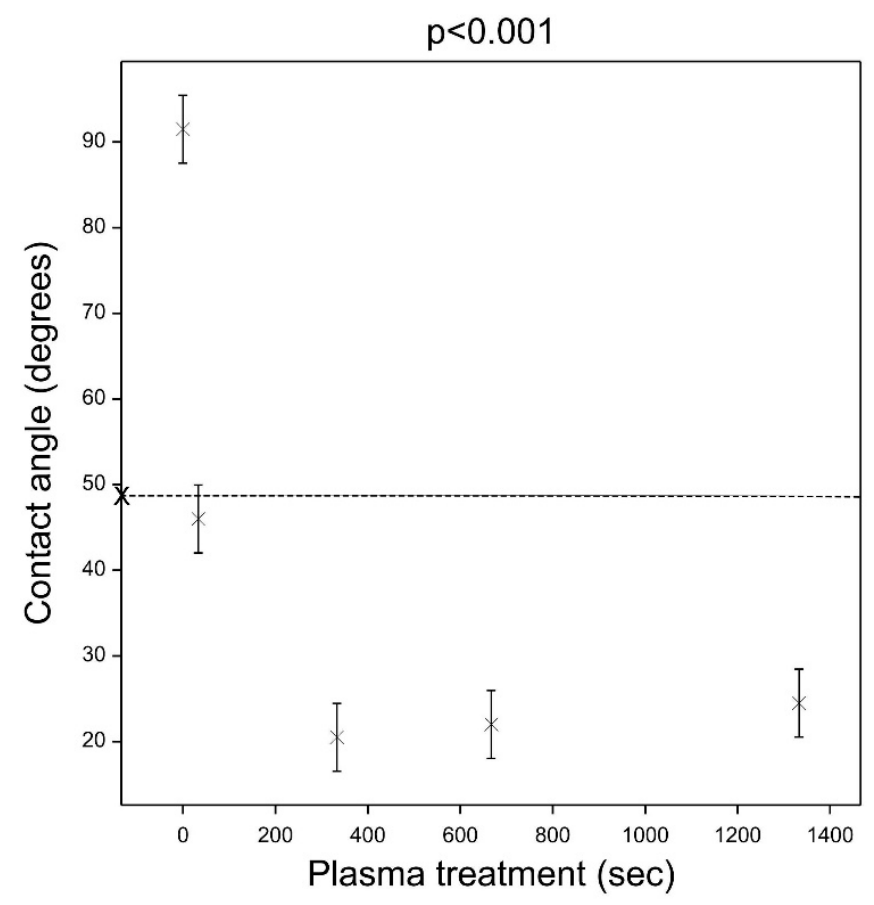

Figure 1. Effect of plasma treatment on the contact angle of water droplets on the surface of hot-oil modified blue-stained lodgepole pine wood. The bold X symbol on the $y$-axis and the horizontal dotted line indicate the contact angle of a water droplet on unmodified blue-stained lodgepole pine wood.

\subsection{Appearance and Microstructure of Hot-Oil and Plasma Treated Wood}

Hot-oil modified wood was a brown colour, in contrast to the blue colour of unmodified blue-stained lodgepole pine wood. The modified wood was dry and appeared to be free of residual oil, but scanning electron microscopy revealed the presence of oil at the surface of hot-oil modified wood (Figure 2). Figure 2a,b shows the surface of unmodified wood. The pine cells (longitudinal tracheids) run obliquely from left to right (Figure 2a,b). A fungal hypha is present in a tracheid lumen in Figure 2a, and circular bordered pits (connections between tracheids) are prominent in both Figure 2a,b (arrowed). After hot-oil modification, oil was present at the surface of modified wood samples (Figure 2c). The oil did not completely cover the surface of the wood, but occluded some tracheids (arrowed in Figure 2c), while others were free of oil (Figure 2c). Plasma treatment of unmodified wood removed (etched) the raised border and the internal membrane (margo and torus) of bordered pits creating large circular voids at the surface of the wood (arrowed in Figure 2d), as we have observed previously with other wood species $[27,28]$.

Plasma treatment of hot-oil modified wood removed deposits of oil from the surface of the wood (Figure 2e), and etched wood cell walls (Figure 2f,g), but there were differences in the etching of unmodified wood and the etching of hot-oil modified wood. In particular, the bordered pit membranes in hot-oil modified wood were resistant to plasma etching (arrowed in Figure 2h), whereas plasma completely removed pit membranes at the surface of unmodified wood (compare Figure 2f,g with Figure 2d). 

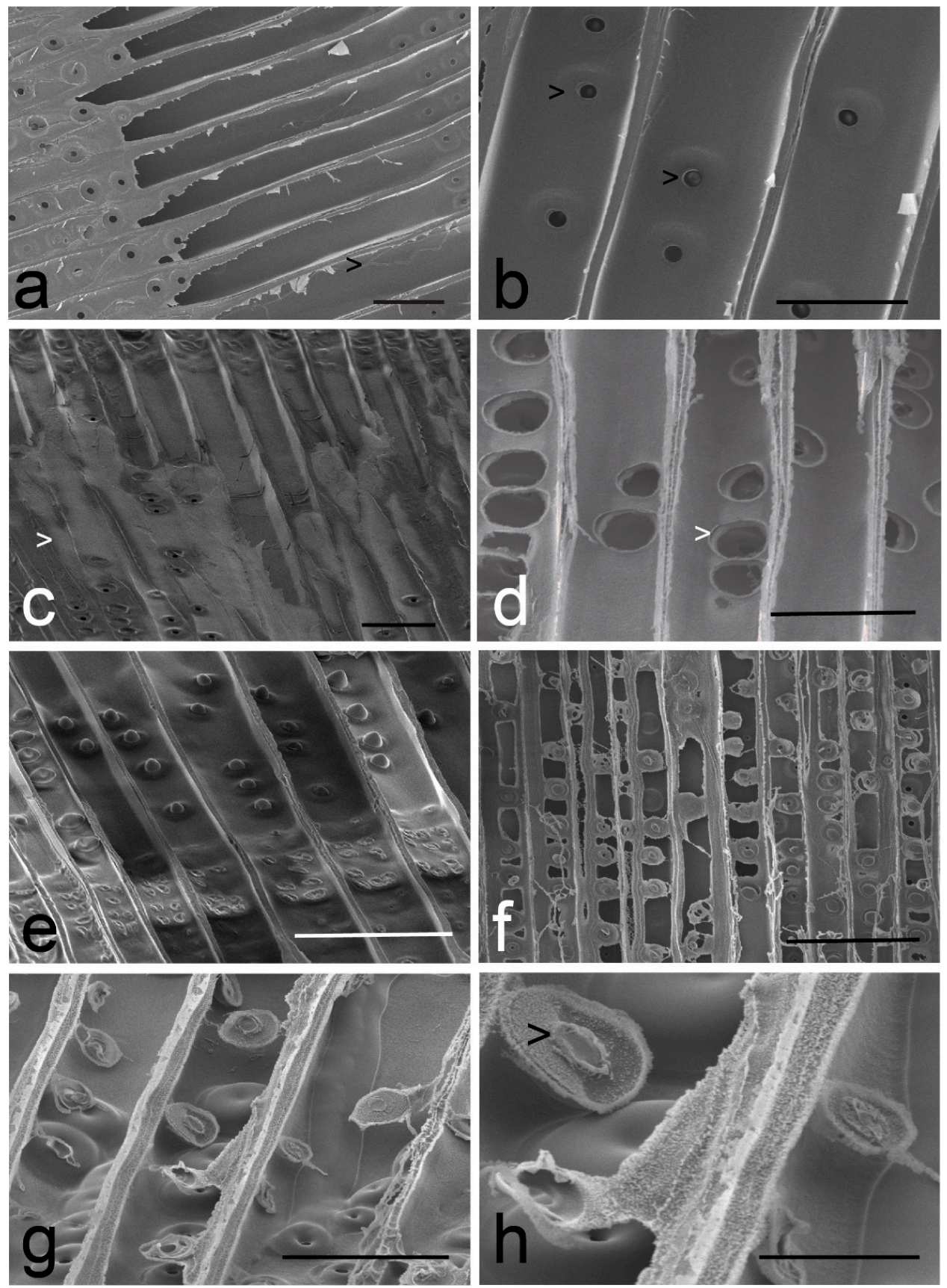

Figure 2. SEM photomicrographs of blue-stained lodgepole pine wood before and after hot-oil modification and plasma treatment: (a) and (b) Unmodified controls; (c) Wood modified with hot-oil; (d) Unmodified wood treated with plasma for $667 \mathrm{~s}$; (e) Hot-oil modified wood treated with plasma for 333 s. Note the ballooning of pit membranes through the aperture of the bordered pits; (f-h) Hot-oil modified wood treated with plasma for $1333 \mathrm{~s}$.

The 'protective' effect of hot-oil modification on plasma etching of bordered pit membranes was confirmed by confocal profilometry of hot-oil modified wood samples before and after plasma treatment. Figure 3 shows topographic images of the surface of hot-oil modified wood before (Figure 3a) and after plasma treatment (Figure $3 \mathrm{~b}, \mathrm{c}$ ). Figure 3a shows the raised borders around two pit apertures at the surface of hot-oil modified wood. After exposure to plasma the border is etched away, as well as some of the adjacent cell wall material (Figure $3 b, c)$. However, the central part of the pit, the pit membrane is still intact (Figure 3b,c). 


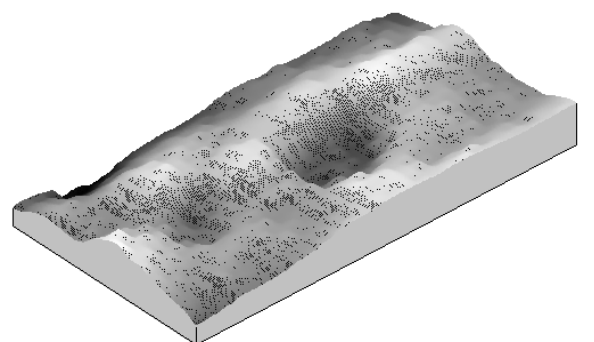

(a)

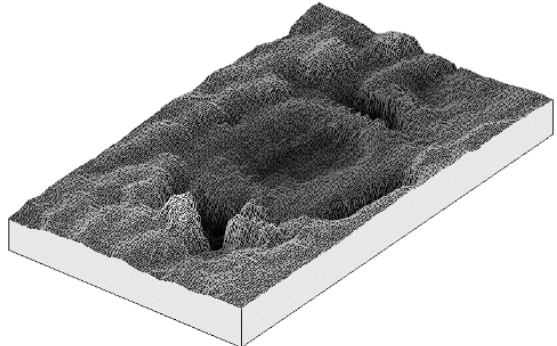

(b)

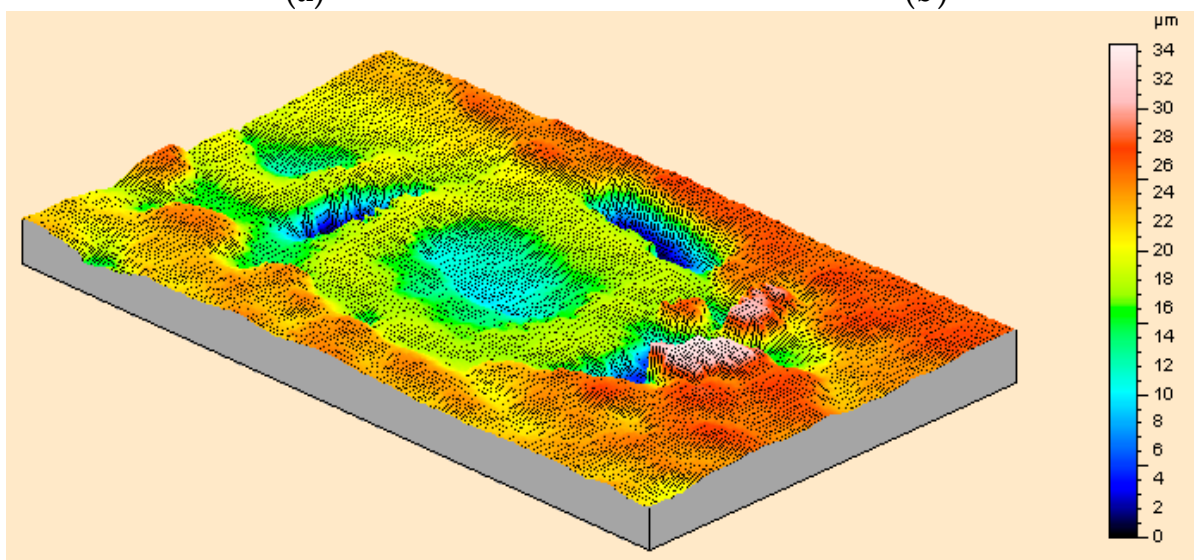

(c)

Figure 3. Confocal profilometry images of the wood cell wall in hot-oil modified wood samples before and after plasma treatment: (a) Two bordered pits in the cell wall of a wood sample modified with hot-oil; (b) and (c) Bordered pit in the cell wall of a wood sample modified with hot-oil and then treated with plasma for $1333 \mathrm{~s}$. Note that the cell wall around the bordered has been etched but the central part of the pit is intact.

\subsection{Performance of an Acrylic Coating on Hot-Oil and Plasma Treated Wood after Natural Weathering}

The appearance of a representative set of coated wood samples that had been hot-oil modified and/or treated with plasma, and then exposed to the weather in Vancouver for 18 months can be seen in Figure $4 \mathrm{~b}, \mathrm{~d}, \mathrm{f}, \mathrm{h}$. Unweathered controls stored in a conditioning room for the duration of the weathering trial are shown on the left-hand side of Figure $4 \mathrm{a}, \mathrm{c}, \mathrm{e}, \mathrm{g}$. The most obvious change in appearance of the samples during exposure to the weather is the more pronounced discolouration of the acrylic coating on the hot-oil modified wood sample (Figure 4d). Some discolouration of the ends of most weathered samples occurred where they were covered with glass strips used to fix them to weathering racks.

The white colour of coated samples was measured using a spectrophotometer, and the CIE parameter L (white to black on a scale of 100 (white) to 0 (black)) was used to assess changes in the colour of the white paint. The colour of coated wood samples that had been hot-oil modified and/or treated with plasma, and stored in a conditioned room for 18 months, or exposed to the weather for a similar period of time can be seen in Figure 5. There were no significant $(p>0.05)$ effects of hot-oil treatment and/or plasma modification on the colour of the white acrylic paint on unweathered samples. The hot-oil and oil and plasma treated samples were slightly darker than the unmodified samples (control and plasma treated), in accord with their appearance in Figure 4, but the differences in colour are not statistically significant $(p>0.05)$ (Figure 5). The paint on all samples became significantly $(p<0.05)$ darker after weathering, but the darkening was most pronounced on hot-oil modified samples. Plasma treatment clearly reduced the darkening of the hot-oil modified samples, although hot-oil modified, plasma treated and weathered samples were significantly $(p<0.05)$ darker than the controls that were not modified with hot-oil (Figure 5). 


\section{Unweathered}

Untreated

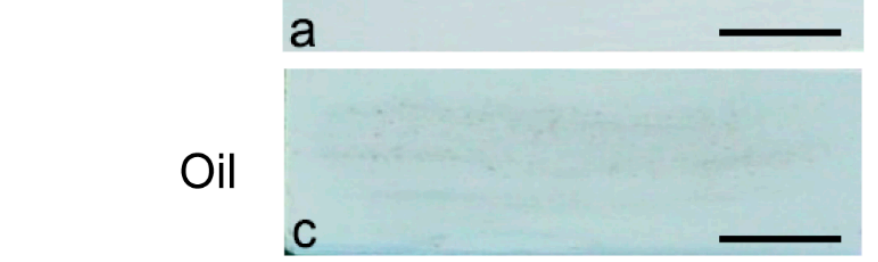

Oil/Plasma

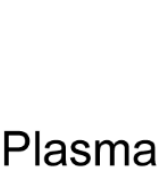

Weathered
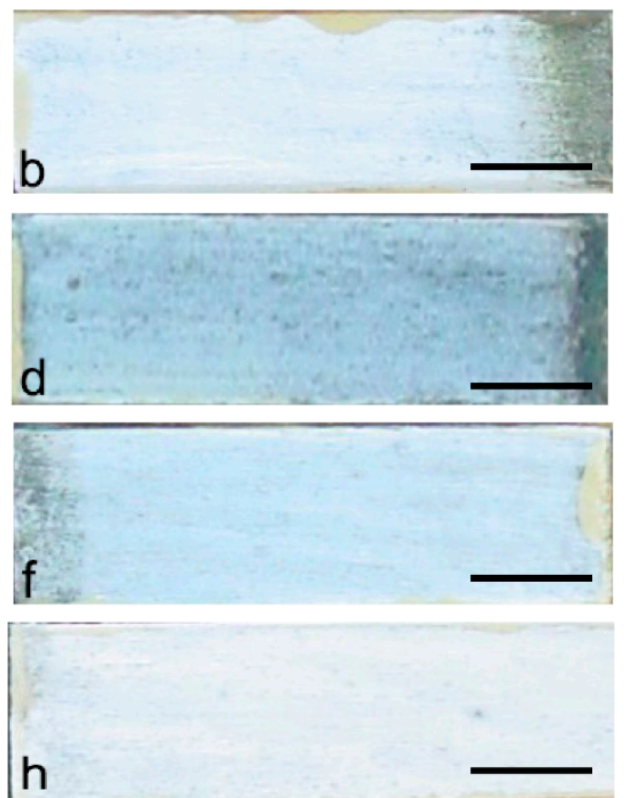

Figure 4. Effects of hot-oil treatment and/or plasma modification on the appearance of an acrylic paint on blue-stained lodgepole pine samples exposed to 18 months of natural weathering (samples $\mathrm{b}, \mathrm{d}, \mathrm{f}, \mathrm{h}$ ). Unweathered controls on left-hand side (samples a,c,e,g) were stored in a conditioning room for 18 months. Scale bars $=11 \mathrm{~mm}$.

There was no significant ( $p>0.05$ ) effect of plasma treatment on water uptake of samples and no significant $(p>0.05)$ interaction of plasma treatment and exterior exposure (unweathered vs. weathered) on water uptake.

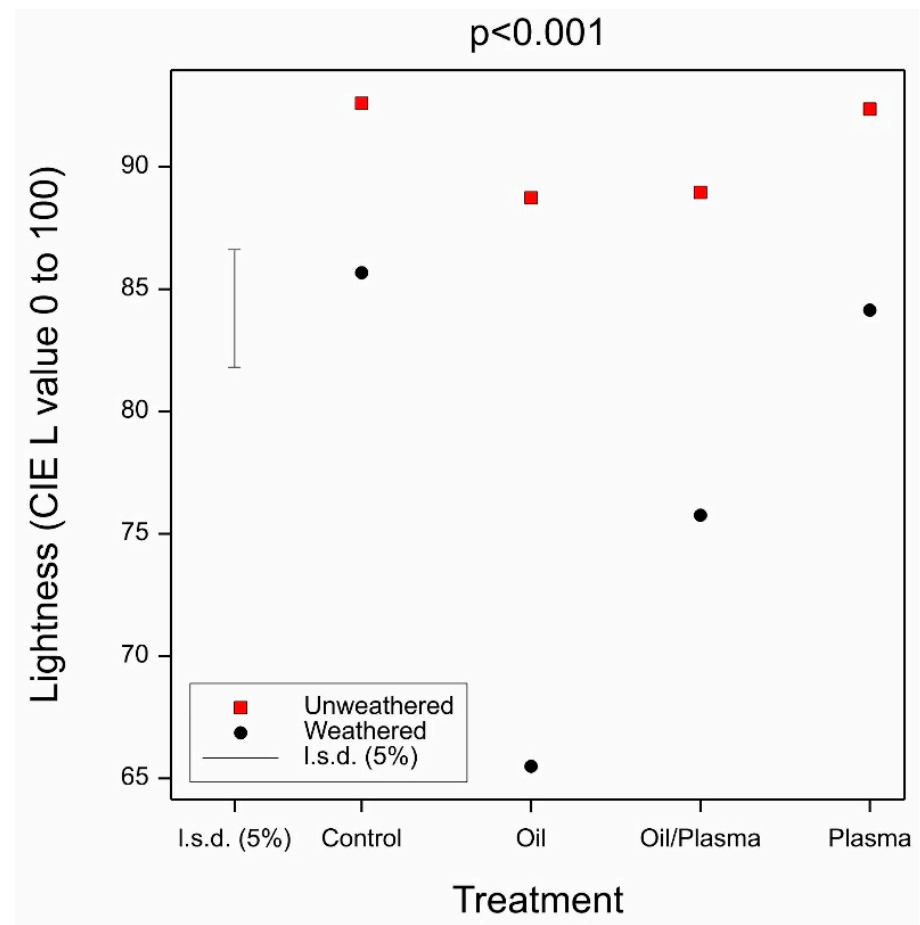

Figure 5. Effects of hot-oil treatment and/or plasma modification on the white colour (CIE L value) of an acrylic paint on blue-stained lodgepole pine samples exposed to 18 months of natural weathering. 


\section{Discussion}

In the introduction to this paper, we hypothesized that plasma treatment would remove residual oil from the surface of hot-oil modified blue-stained lodgepole pine wood, and this would have beneficial effects on the adhesion and performance of an acrylic coating on wood. Our results partially support this hypothesis. Oil was present at the surface of hot-oil modified wood and significantly increased the hydrophobicity of the wood (contact angle of greater than 90 degrees). However, after plasma modification the contact angle of hot-oil modified wood was lower than that of wood in its native state suggesting that plasma removed oil from wood surfaces. Scanning electron microscopy confirmed that oil was absent from hot-oil modified wood surfaces that were treated with plasma, and it also revealed extensive etching of wood cell walls. Hence, we conclude that plasma is able to remove oil from the surface of hot-oil modified wood, in accord with previous studies that have shown that plasma can remove oil from the surface of metals and polymers [19,20].

Plasma treatments have been tested to determine if they can improve the adhesion of coatings to different wood species [35], heat-treated wood [11] and wood composites [36]. Oil at the surface of wood is reported to reduce coating adhesion [15], but we found that removal of oil from the surface of hot-oil modified blue-stained lodgepole pine wood by plasma did not alter the adhesion of an acrylic primer to the modified wood. This runs counter to our hypothesis, but accords with the findings of Podgorski and coworkers who found that a plasma treatment did not improve the adhesion of coatings to heat-treated wood, even though their plasma treatment made the surface more wettable [7]. A number of other studies have shown that plasma pre-treatments have no, or even negative, effects on the adhesion of coatings to unmodified wood $[37,38]$. The adhesion of the acrylic coating to replicates obtained from different wood samples was highly variable, and this would have reduced the ability to detect statistically significant $(p<0.05)$ plasma-treatment effects on coating adhesion. In general, our findings accord with those of Acda and coworkers who concluded that "effects of plasma treatment on the adhesion of coatings to wood vary with wood substrate and process parameters" [35]. Nevertheless, removal of surface oil from hot-oil modified wood samples by plasma improved the performance of the acrylic paint by reducing the discolouration of the paint on samples exposed outdoors to the weather.

The discolouration of paint films is an important criterion used to assess the performance of paint films exposed outdoors [39]. Several approaches are used to reduce such discolouration including modifications to coatings to reduce pickup by dirt, and the use of biocides to reduce colonization of paint by micro-organisms [39]. Therefore, our finding that plasma treatment significantly reduced the discolouration of an acrylic paint on hot-oil modified wood is noteworthy, but further research is needed to determine whether the same effect occurs with other coatings, some of which are less permeable than acrylic paints, for example water-borne alkyds and mixed alkyd-acrylic systems [40]. Further research is also needed to determine the identity of the agents responsible for the discolouration of the acrylic paint on hot-oil modified wood, which could include dirt [39], mould $[17,25,26]$ and algae [41]. Plasma treatment did not completely eliminate discolouration of the acrylic paint on hot-oil modified wood. One possible explanation for this observation is that plasma only removed oil from the surface of the wood, and subsequent migration of oil from the interior of samples to the surface of wood during weathering encouraged some discolouration of hot-oil modified plasma-treated wood samples. Further research would be needed to confirm this hypothesis, which is supported by previous studies that have shown that oils migrate to the surface of preservative treated wood exposed to natural weathering [42,43].

One unexpected finding arising from our work was the effect that oil modification had on the etching of bordered pits. These pits act as conduits allowing the passage of liquids (including oils) and gases between cells (tracheids) in softwood species. They contain a cellulosic membrane (the margo) and a centrally thickened torus. Pit membranes in untreated wood are rapidly etched by plasma $[27,28]$, and they are also highly susceptible to microbial degradation [44]. However, remnants of pit membranes were commonly observed at the surface of hot-oil modified and plasma treated wood, whereas they were absent from the surface of unmodified plasma treated controls. This finding 
suggests that hot-oil modification reduced the susceptibility of pit membranes to plasma etching, possibly in accord with previous research that has shown that oils increase the oxidative stability of cellulosic substrates [45].

One feature of the hot-oil thermal modification process is that oil is absorbed and retained by the modified wood [46]. This oil contributes to the desirable water repellency of hot-oil modified wood [5], but as we have shown here, it appears to have an undesirable effect on the exterior performance of an acrylic coating. We are unable to compare our results with those of others because there has been no related work on the use of plasma treatments to improve the performance of coatings on hot-oil modified wood. Plasma treatments are used to remove oils from the surfaces of metals and polymers, as mentioned above [19-21], and are preferred to solvent cleaning systems because they do not generate waste that requires disposal. Solvent wiping is used to remove oil from oily woods such as teak, and to improve the performance of coatings on the wood, as mentioned in the introduction [22]. Therefore, it is possible that plasma cleaning systems could emerge to replace solvent wiping systems and improve coating performance on woods that contain oil, either naturally or as a result of hot-oil modification. However, the plasma treatment system used here would not be suitable for commercial applications because it required high vacuum, relatively long treatment times, and it is unable to treat large samples. Furthermore, our findings need to be replicated with additional wood species and oils that are used to manufacture hot-oil modified wood, and complimented by further studies that examine chemical and physical changes resulting from plasma treatment of hot-oil modified wood (FTIR and polar and dispersive components of surface energy changes). Nevertheless, we conclude that plasma treatment shows promise as a way of improving the performance of exterior acrylic coatings on hot-oil modified wood, but commercial applications would require the development of treatment technology that can more rapidly remove oil from the surface of modified wood.

\section{Conclusions}

A water-vapor plasma pre-treatment reduced the discolouration of a water-borne acrylic latex coating on hot-oil modified, blue-stained lodgepole pine wood exposed to natural weathering for 18 months. We identified that the ability of plasma to remove oil from the surface of the modified wood was responsible for the reduced discolouration of the coating on hot-oil modified wood. We conclude that plasma treatment shows promise as a way of improving the outdoor performance of white acrylic paint on hot-oil modified wood. Further research on plasma modification to improve the performance of coatings on hot-oil modified wood will focus on trialing the treatment on additional wood species and using different oils that are used to manufacture hot-oil modified wood, and developing treatment technology that can more rapidly remove oil from the surface of modified wood.

Supplementary Materials: The following are available online at http://www.mdpi.com/2079-6412/10/3/248/s1, Figure S1: Images of hot-modified and plasma-treated samples after cross-cut adhesion testing.

Author Contributions: A.J. and P.D.E. conceived and designed the experiments; A.J. performed all experimental work. P.D.E. analyzed all data and wrote the first draft of the paper. Both authors discussed and commented on the results and contributed to the final submitted manuscript. All authors have read and agreed to the published version of the manuscript.

Funding: This research was funded by ForValueNet-NSERC strategic network on forest management for value-added products, grant numbers NSERC 340830-06 and 03701-CG08822; NSERC Collaborative Research and Development Grant (CRDPJ 485007-15); Forestry Innovation Investment Market Development Program 08-52; Rix Family Foundation Award to A.J.

Acknowledgments: We thank Ian Cullis, Mohammad Jahangir Chowdhury and Lukie H. Leung for technical assistance; Canadian Foundation for Innovation, BC Knowledge Development Fund and FPInnovations for in-kind support. P.D.E. thanks Viance, Tolko, FPInnovations, Faculty of Forestry (UBC) and the Government of British Columbia for their support of his BC Leadership Chair at the University of British Columbia, and The Australian National University (ANU) for an Honorary Professorship in the Department of Applied Mathematics, Research School of Physics at the ANU.

Conflicts of Interest: The authors declare that they have no affiliations with or involvement with organizations that have financial interests in the subject matter or materials discussed in this paper. 


\section{References}

1. Boenig, H.V. Plasma Science and Technology; Cornell University Press: New York, NY, USA, 1982.

2. Kaplan, S.L.; Rose, P.W. Plasma surface treatment of plastics to enhance adhesion. Int. J. Adhes. Adhes. 1991, 11, 109-113. [CrossRef]

3. Suchentrunk, R.; Fuesser, H.J.; Staudigl, G.; Jonke, D.; Meyer, M. Plasma surface engineering-Innovative processes and coating systems for high-quality products. Surf. Coat. Technol. 1999, 112, 351-357. [CrossRef]

4. Hakkou, M.; Pétrissans, M.; Zoulalian, A.; Gérardin, P. Investigation of wood wettability changes during heat treatment on the basis of chemical analysis. Polym. Degrad. Stab. 2005, 89, 1-5. [CrossRef]

5. Hill, C.A. Wood Modification: Chemical, Thermal and Other Processes; John Wiley \& Sons: Hoboken, NJ, USA, 2007.

6. Jirouš-Rajković, V.; Miklečić, J. Heat-treated wood as a substrate for coatings, weathering of heat-treated wood, and coating performance on heat-treated wood. Adv. Mater. Sci. Eng. 2019, 2019, 8621486. [CrossRef]

7. Podgorski, L.; Chevet, B.; Onic, L.; Merlin, A. Modification of wood wettability by plasma and corona treatments. Int. J. Adhes. Adhes. 2000, 20, 103-111. [CrossRef]

8. Wolkenhauer, A.; Avramidis, G.; Militz, H.; Viöl, W. Plasma treatment of heat treated beech wood-investigation on surface free energy. Holzforschung 2008, 62, 472-474. [CrossRef]

9. Avramidis, G.; Militz, H.; Avar, I.; Viöl, W.; Wolkenhauer, A. Improved absorption characteristics of thermally modified beech veneer produced by plasma treatment. Eur. J. Wood Wood Prod. 2012, 70, 545-549. [CrossRef]

10. Talviste, R.; Galmiz, O.; Stupavská, M.; Tučeková, Z.; Kaarna, K.; Kováčik, D. Effect of DCSBD plasma treatment on surface properties of thermally modified wood. Surf. Interfaces 2019, 16, 8-14. [CrossRef]

11. Van Nguyen, T.H.; Nguyen, T.T.; Ji, X.; Guo, M. Enhanced bonding strength of heat-treated wood using a cold atmospheric-pressure nitrogen plasma jet. Eur. J. Wood Wood Prod. 2018, 76, 1697-1705. [CrossRef]

12. Lee, S.H.; Ashaari, Z.; Lum, W.C.; Halip, J.A.; Ang, A.F.; Tan, L.P.; Chin, K.L.; Tahir, P.M. Thermal treatment of wood using vegetable oils: A review. Constr. Build. Mater. 2018, 181, 408-419. [CrossRef]

13. Manolache, S.; Jiang, H.; Rowell, R.M.; Denes, F.S. Hydrophobic wood surfaces generated by non-equilibrium, atmospheric pressure (NEAPP) plasma-enhanced coating. Mol. Cryst. Liq. Cryst. 2008, 483, 348-351. [CrossRef]

14. Petrič, M.; Knehtl, B.; Krause, A.; Militz, H.; Pavlič, M.; Pétrissans, M.; Rapp, A.; Tomažič, M.; Welzbacher, C.; Gérardin, P. Wettability of waterborne coatings on chemically and thermally modified pine wood. J. Coat. Technol. Res. 2007, 4, 203-206. [CrossRef]

15. Nejad, M.; Shafaghi, R.; Ali, H.; Cooper, P. Coating performance on oil-heat treated wood for flooring. BioResources 2013, 8, 1881-1892. [CrossRef]

16. Hse, C.Y.; Kuo, M.L. Influence of extractives on wood gluing and finishing-a review. For. Prod. J. 1988, 38, 52-56.

17. Gobakken, L.R.; Westin, M. Surface mould growth on five modified wood substrates coated with three different coating systems when exposed outdoors. Int. Biodeterior. Biodegrad. 2008, 62, 397-402. [CrossRef]

18. Harford, C.G. Corrosion Inhibiting Composition for Coating Metal, Coated Metal and Method of Coating. U.S. Patent 2,816,051, 10 December 1957.

19. Belkind, A.; Zarrabian, S.; Engle, F. Plasma cleaning of metals: Lubricant oil removal. Metal Finish. 1996, 94, 19-22. [CrossRef]

20. Keller, M.; Ritter, A.; Reimann, P.; Thommen, V.; Fischer, A.; Hegemann, D. Comparative study of plasma-induced and wet-chemical cleaning of synthetic fibers. Surf. Coat. Technol. 2005, 200, 1045-1050. [CrossRef]

21. Krüger, P.; Knes, R.; Friedrich, J. Surface cleaning by plasma-enhanced desorption of contaminants (PEDC). Surf. Coat. Technol. 1999, 112, 240-244. [CrossRef]

22. Frihart, C.R.; Wiedenhoeft, A.C.; Jakes, J.E. Wood bonding in the furniture industry and the effect of changing wood supply. In Proceedings of the COST E34 Workshop on Practical Solutions for Furniture and Structural Bonding, Larnaka, Cyprus, 22-23 March 2007; pp. 11-18.

23. Kurz, W.A.; Dymond, C.C.; Stinson, G.; Rampley, G.J.; Neilson, E.T.; Carroll, A.L.; Ebata, T.; Safranyik, L. Mountain pine beetle and forest carbon feedback to climate change. Nature 2008, 452, 987-990. [CrossRef]

24. Cai, J.; Cai, L. Effects of thermal modification on mechanical and swelling properties and color change of lumber killed by mountain pine beetle. BioResources 2012, 7, 3488-3499. 
25. Gobakken, L.R.; Høibø, O.A.; Solheim, H. Mould growth on paints with different surface structures when applied on wooden claddings exposed outdoors. Int. Biodeterior. Biodegrad. 2010, 64, 339-345. [CrossRef]

26. Bardage, S.L. Susceptibility of painted wood to Aureobasidium pullulans: Fungal stain and growth patterns. Holz Roh-u Werkst. 1998, 56, 359-364. [CrossRef]

27. Jamali, A.; Evans, P.D. Etching of wood surfaces by glow discharge plasma. Wood Sci. Technol. 2011, 45, 169-182. [CrossRef]

28. Haase, J.G.; Leung, L.H.; Evans, P.D. Plasma pre-treatments to improve the weather resistance of polyurethane coatings on black spruce wood. Coatings 2019, 9, 8. [CrossRef]

29. Thay, P.D.; Evans, P.D. The adhesion of an acrylic primer to weathered radiata pine surfaces. Wood Fiber Sci. 2007, 30, 198-204.

30. ASTM D3359-09. Standard Test Methods for Measuring Adhesion by Tape Test; ASTM: West Conshohocken, PA, USA, 2010.

31. Williams, L.J.; Hervé, A. Fisher's least significant difference (LSD) test. In Encyclopedia of Research Design; Salkind, N., Ed.; SAGE: Thousand Oaks, CA, USA, 2010; p. 6.

32. Heady, R.D.; Banks, J.G.; Evans, P.D. Wood anatomy of Wollemi pine (Wollemia nobilis, Araucariaceae). IAWA J. 2002, 23, 339-357. [CrossRef]

33. Thompson, D.W.; Kozak, R.A.; Evans, P.D. Thermal modification of color in red alder veneer. I. Effects of temperature, heating time, and wood type. Wood Fiber Sci. 2007, 37, 653-661.

34. Kiguchi, M.; Kataoka, Y.; Suzuki, M.; Imamura, Y. Progress towards the service life prediction of coatings for exterior wood by weathering test trials. In Service Life Prediction: Challenging the Status Quo; Martin, J.W., Ryntz, R.A., Dickie, R.A., Eds.; Federation of Societies for Coatings Technology: Bluebell, PA, USA, 2005; pp. 123-134.

35. Acda, M.N.; Devera, E.E.; Cabangon, R.J.; Ramos, H.J. Effects of plasma modification on adhesion properties of wood. Int. J. Adhes. Adhes. 2012, 32, 70-75. [CrossRef]

36. De Cademartori, P.H.; de Carvalho, A.R.; Marangoni, P.R.; Berton, M.A.; Blanchet, P.; de Muniz, G.I.; Magalhães, W.L. Adhesion performance and film formation of acrylic emulsion coating on medium density fiberboard treated with Ar plasma. Int. J. Adhes. Adhes. 2016, 70, 322-328. [CrossRef]

37. Podgorski, L.; Roux, M.L. Wood modification to improve the durability of coatings. Surf. Coat. Int. 1999, 82, 590-596. [CrossRef]

38. Cho, D.L.; Sjöblom, E. Plasma treatment of wood. J. Appl. Polymer Sci. 1990, 46, 461-472. [CrossRef]

39. Wagner, O.; Baumstark, R. How to control dirt pick-up of exterior coatings. Macromol. Symp. 2002, 187, 447-458. [CrossRef]

40. De Meijer, M.; Creemers, J.; Cobben, W. Relationships between the performance of low-VOC wood coatings and the dimensional changes of the wooden substrate. Surf. Coat. Int. Part B Coat. Trans. 2001, 84, 77-85. [CrossRef]

41. Bjurman, J. Algal growth resistance of paints for coating of wood: A laboratory study. In Proceedings of the International Research Group on Wood Protection Meeting, Whistler, BC, Canada, 25-30 May 1997.

42. Baileys, R.T.; Webb, D.A. 1958 Cooperative creosote project-XII: An analysis of creosotes from posts after 26 years in test. In Proceedings of the Eighty-Third Annual Meeting of the American Wood-Preservers' Association, Toronto, ON, Canada, 10-13 May 1987; pp. 163-171.

43. Bulle, C.S.; Samson, R.; Deschênes, L. Transport of chlorinated dioxins and furans in soil columns: Modeling pentachlorophenol pole-treating oil influence. Chemosphere 2011, 83, 117-123. [CrossRef] [PubMed]

44. Burnes, T.A.; Blanchette, R.A.; Farrell, R.L. Bacterial biodegradation of extractives and patterns of bordered pit membrane attack in pine wood. Appl. Environ. Microbiol. 2000, 66, 5201-5205. [CrossRef] [PubMed]

45. Coulibaly, M.L.; Perrier, C.; Marugan, M.; Beroual, A. Aging behavior of cellulosic materials in presence of mineral oil and ester liquids under various conditions. IEEE Trans. Dielectr. Electr. Insul. 2013, 20, 1971-1976. [CrossRef]

46. Esteves, B.; Pereira, H. Wood modification by heat treatment: A review. BioResources 2008, 4, 370-404.

(C) 2020 by the authors. Licensee MDPI, Basel, Switzerland. This article is an open access article distributed under the terms and conditions of the Creative Commons Attribution (CC BY) license (http://creativecommons.org/licenses/by/4.0/). 